\title{
Training surgeons in shared decision-making with cancer patients aged 65 years and older: a pilot study
}

\author{
Noralie H Geessink ${ }^{1,2}$ \\ Yvonne Schoon ${ }^{1,2}$ \\ Marcel GM Olde Rikkert ${ }^{\prime}$ \\ Harry van Goor ${ }^{3}$ \\ 'Department of Geriatric Medicine, \\ ${ }^{2}$ Radboud Institute for Health \\ Sciences, ${ }^{3}$ Department of Surgery, \\ Radboud University Medical Center, \\ Nijmegen, The Netherlands
}

This article was published in the following Dove Press journal:

Cancer Management and Research

10 November 2017

Number of times this article has been viewed

Objective: Treatment decision-making in older patients with colorectal (CRC) or pancreatic cancer (PC) needs improvement. We introduced the EASYcare in Geriatric Onco-surgery (EASY-GO) intervention to optimize the shared decision-making (SDM) process among these patients.

Methods: The EASY-GO intervention comprised a working method with geriatric assessment and SDM training for surgeons. A non-equivalent control group design was used. Newly diagnosed CRC/ PC patients aged $\geq 65$ years were included. Primary patient-reported experiences were the quality of SDM (SDM-Q-9, range 0-100), involvement in decision-making (Visual Analog Scale for Involvement in the decision-making process [range 0-10]), satisfaction about decision-making (Visual Analog Scale for Satisfaction concerning the decision-making process [range 0-10]), and decisional regret (Decisional Regret Scale [DRS], range 0-100). Only for DRS, lower scores are better.

Results: A total of $71.4 \%$ of the involved consultants and $42.9 \%$ of the involved residents participated in the EASY-GO training. Only 4 trained surgeons consulted patients both before $(n=19)$ and after $(n=19)$ training and were consequently included in the analyses. All patientreported experience measures showed a consistent but non-significant change in the direction of improved decision-making after training. According to surgeons, decisions were significantly more often made together with the patient after training (before, $38.9 \%$ vs after, $73.7 \%, p=0.04$ ). Sub-analyses per diagnosis showed that patient experiences among older PC patients consistent and clinically relevant changed in the direction of improved decision-making after training (SDM-Q-9 + 13.4 [95\% CI -7.9; 34.6], VAS-I +0.27 [95\% CI -1.1; 1.6], VAS-S +0.88 [95\% CI $-0.5 ; 2.2]$, DRS -10.3 [95\% CI -27.8; 7.1]).

Conclusion: This pilot study strengthens the practical potential of the intervention's concept among older surgical cancer patients.

Keywords: shared decision making, training program, surgeons, elderly, colorectal cancer, pancreatic cancer

\section{Introduction}

Major surgery in older cancer patients results in significant risks of complications that may jeopardize patients' quality of life and functioning. ${ }^{1,2}$ Multi-morbidity and frailty are important elements in the surgical risk evaluation of these patients. ${ }^{3}$ Colorectal (CRC) and pancreatic cancer (PC) resections in older patients are common examples of high-risk procedures, and decision-making in this context may still be improved considerably. ${ }^{4-6}$ For older CRC and PC patients and their families, it is important to understand what they can expect after surgery and how surgery may impact their daily life. $^{7}$ To adequately inform older patients, surgeons should integrate information on their physical and psychosocial problems, including the overall frailty. ${ }^{7}$ However, this
Correspondence: Yvonne Schoon Department of Geriatric Medicine, Radboud university medical center, $\mathrm{PO}$ 910I (HP 925), 6500 HB Nijmegen, The Netherlands

Tel +3I $2436 \mid 6772$

Email Yvonne.Schoon@radboudumc.nl 
is a difficult task, and while preoperative geriatric assessment is recommended in many oncologic guidelines, it is usually limited to an anesthesiologic risk evaluation about the patient's fitness for surgery. ${ }^{8}$ Non-geriatric physicians are often overwhelmed by the complexity of geriatric patients..$^{9,10}$ In addition, specific geriatric training in surgical curricula is minimal or lacking, ${ }^{11}$ and there is room for improvement in implementing basic geriatrics. ${ }^{12,13}$ Moreover, to involve patients in decision-making and deliver patient-preferred care, shared decision-making (SDM) and shared goal-setting are widely recommended for surgical procedures in these frail patients where alternatives for a major operation are available. ${ }^{3,14,15}$ Previous studies show that surgeons' SDM skills can be optimized ${ }^{16,17}$ specifically among older patients. ${ }^{18,19} \mathrm{We}$ developed the EASYcare in Geriatric Onco-surgery (acronym EASY-GO) intervention, which is a multi-component intervention designed to optimize the SDM process among older CRC and PC patients. In this paper, we present the proof of concept of such a training intervention, based on a pilot study in surgical practice.

\section{Methods}

\section{EASY-GO intervention}

The EASY-GO intervention comprised an EASY-GO training for surgeons and nurse specialists focused on frailty and SDM after which the EASY-GO working method was implemented. According to this method, nurse specialists accomplished competencies in geriatric screening and surgeons applied SDM in their consultations.

\section{EASY-GO training}

The EASY-GO training for surgeons and nurse specialists lasted two sessions of two hours and two sessions of three hours, respectively. In the first session, participants were educated about frailty and geriatric screening during which quizzes, role plays, and case discussions were alternated. Knowledge about frailty and numbers of adverse outcomes in surgical elderly care was transferred by presentations. Active discussions took place using case descriptions. All case descriptions were derived from daily practice, e.g., baseline measurement. Discussion points included the following: is this patient frail and why? Since the EASYcare instrument (which comprised a brief standardized method of assessing the health and care needs perceptions of older people), ${ }^{20}$ the Mini-Mental State Examination (MMSE), the Geriatric Depression Scale 15 (GDS-15), and gait speed were part of the screening, these instruments including their interpretation were also explained during the first training day. The second training session focused on SDM. In a presentation, the theory of SDM and a model for clinical practice (based on the models of Elwyn, ${ }^{14}$ Makoul, ${ }^{15}$ and Van de Pol et al, ${ }^{21}$ respectively) were discussed. Subsequently, the implementation of SDM and difficult conversations were practiced with an actor. Again, used case descriptions were derived from baseline measurement. At last, the EASY-GO working method was explained. The four trainers for all sessions were as follows: a GP specialized in SDM, elderly, and education; a geriatrician specialized in preoperative elderly care and education; and two geriatric nurse specialists. For surgeons, the training was offered on a voluntary basis.

\section{EASY-GO working method}

After training, the EASY-GO working method was implemented with a few procedures added to usual care (Figure 1). First, the nurse specialists performed 60 minutes of geriatric screening in all patients aged $\geq 65$ years using the EASYcare instrument, MMSE, GDS-15, and gait speed. Since older $\mathrm{CRC} / \mathrm{PC}$ patients and their physicians considered "obtaining an overall picture" and "taking into account frailty", respectively, a key element in optimal decision-making, ${ }^{7}$ we introduced the geriatric assessment as part of the EASY-GO intervention. In addition, patients' goals in life and treatment preferences were discussed. In case of a lack of time or organizational issues, the screenings were accomplished by one of the researchers $(\mathrm{NG})$. Afterward, results of the geriatric screening were provided to the surgeon before the surgeon welcomed the patient in the consultation room. Subsequently, trained surgeons applied SDM in the consultations taking into account the personal context of the patient. In general, treatment options for patients with CRC and PC (depending on cancer stage) include surgery, (neo)adjuvant chemotherapy and/or radiotherapy (frequently in the context of a clinical trial), and no treatment. Adherence to the intervention was stimulated by training-on-the-job performed by a geriatric specialist; the surgeons received feedback post-consultation about the SDM process, and nurse specialists received feedback about the geriatric screening.

\section{Study design}

Our multi-component training intervention was implemented and evaluated as part of a practice-based pilot study. A non-equivalent control group design was used. Before the EASY-GO training took place, a baseline measurement was conducted. After training, a posttest was carried out within 
Pre-training

If applicable: diagnostic information for surgeon by referral letter
Information provision to patient by surgeon in the presence of nurse specialist
Arranging logistics and handover information folder by nurse specialist
Post-training

EASY-GO training

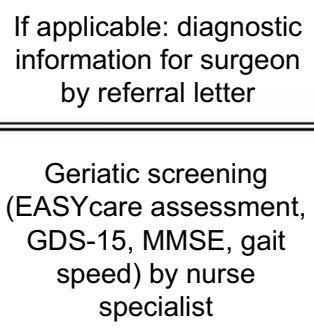

If applicable: diagnostic information for surgeon by referral letter

Geriatic screening (EASYcare assessment, GDS-15, MMSE, gait speed) by nurse specialist

Discussion of patient's treatment and life goals by nurse specialist

Provision results geriatic screening to surgeon

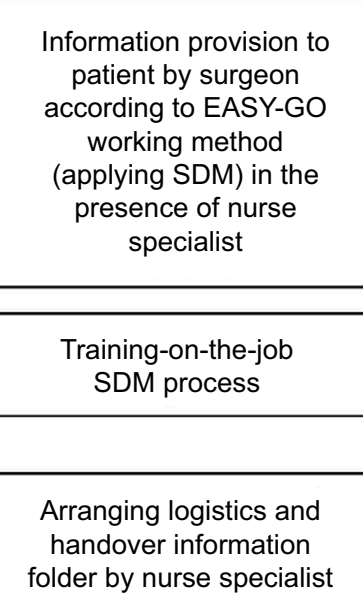

Figure I EASY-GO intervention positioned in EASY-GO pilot study. Abbreviations: EASY-GO, EASYcare in Geriatric Onco-surgery; EASYcare, Elderly Assessment System care; GDS-15, Geriatric Depression Scale, I5 items; MMSE, MiniMental State Examination; SDM, shared decision-making.

a new group of patients. The EASY-GO intervention was implemented in the regular care processes for CRC and PC patients. No selection was made which surgeon consulted the patient. To analyze the implementation of the EASY-GO intervention, a process evaluation was also conducted.

\section{Setting and participants}

Consecutive patients were included at the surgical department of the Radboud university medical center, Nijmegen, the Netherlands. Inclusion criteria were as follows:
- Patients $\geq 65$ years

- Patients registered as new patient diagnosed with CRC or PC (for patients with CRC in some cases with localized metastases)

- Patients initially considered for surgery (whereby it was allowed that patients with rectal cancer already had had neoadjuvant radiotherapy and/or chemotherapy).

All consultations were observed by one of the researchers (NG). All consultants, residents, and nurse specialists involved in the abdominal oncology care in the study's time 
frame were included in the pilot study. Patients did not know whether their physician was trained or not.

\section{Outcome measures and data collection Effects of EASY-GO intervention}

Primary outcomes were four patient-reported experience measures (PREMs): patient-reported level of SDM, patient involvement in decision-making, patient satisfaction about the decision-making process, and patient's decisional regret. Secondary outcomes were two patient-reported outcome measures (PROMs) on patient's quality of life and quality of functioning. For the primary outcomes, patients filled in a questionnaire at home after the final consultation when the treatment decision was made (T0). This questionnaire included the nine-item Shared Decision Making Questionnaire (SDMQ-922,23) for the patient-reported level of SDM (scale 0-100, where 0 indicates the lowest possible level of SDM and 100 indicates the highest extent of SDM). Since the SDM-Q-9 consists of nine statements rated on a six-point scale, raw total scores $(0-45)$ were multiplied by $20 / 9$ to rescale the total range from 0 to 100 . The questionnaire also included visual analog scale scores (VAS-scores; scale 0-10, where 10 indicates the best score) for the extent of involvement in decision-making (VAS-I) and patient satisfaction concerning the decisionmaking process (VAS-S). After three months, patients were again asked to fill in a questionnaire (T1) which concerned decisional regret (Decisional Regret Scale [DRS]; ${ }^{24}$ scale $0-100$, where 0 indicates no decisional regret and 100 indicates high regret). For the secondary outcomes, patients filled in the Older Persons and Informal Caregivers Survey Minimum Dataset (TOPICS-MDS) questionnaire, ${ }^{25}$ both at T0 and at $\mathrm{T} 1$ to measure the quality of life (EuroQol five dimensional scale [EQ5D]; scale -0.33-1.00, where 1 indicates the highest quality of life) and quality of functioning (KATZ index of independence in activities and instrumental activities in daily living [KATZ-15]; scale 0-15, whereby higher scores indicate more disabilities). In addition to the primary and secondary outcomes, patients were additionally asked about who made the decision (adjusted Control Preference Scale $\left.\left[\mathrm{aCPS}_{\mathrm{T} 0}\right]\right)^{26,27}$ at T0 and which role they preferred in decision-making in hindsight (adjusted Control Preference Scale $\left[\mathrm{aCPS}_{\mathrm{T} 1}\right]$ ) at T1. In addition to patients, surgeons also filled in a short questionnaire immediately after the final consultation to determine patient involvement in decision-making (VAS- $\mathrm{I}_{\mathrm{doc}}$ ) and to determine who made the decision according to them $\left(\mathrm{aCPS}_{\mathrm{doc}}\right)$.

To analyze the process of implementation of the EASYGO intervention, the adherence to all intervention components was documented.

\section{Data analysis}

For our analyses, we only included surgeons who consulted patients both before and after implementation of the intervention to be able to analyze the change in their SDM skills. In addition, surgeons who did not participate in the EASY-GO training were excluded in the analyses to be able to evaluate the implementation of the complete EASY-GO intervention like the intended design. To compare baseline characteristics before and after implementation, Student's $t$-test was used for continuous data, chi-square test was used to compare categorical data, and Fisher's exact test was used in case of small numbers per category. Differences were considered statistically significant if the $p$-value was $<0.05$ (for two-tailed tests). For evaluating differences in primary and secondary outcomes before and after implementation of the intervention, a linear mixed model was used to account for clustering within individual surgeons. Sub-analyses were performed per diagnosis, CRC or PC. Change in PREMs was considered clinically relevant if the SDM-Q-9 score differed by $\geq 10$, if the VAS-I and VAS-S scores differed by $\geq 1$, and if the DRS score differed by $\geq-10$. ADL decline was considered clinically relevant if the KATZ-15 score differed by $\geq 1$ points between $\mathrm{T} 0$ and $\mathrm{T} 1$. Change in quality of life was considered clinically relevant if the EQ5D score differed by $\geq 0.10$ points. Data were analyzed using the statistical software program SPSS version 22. With respect to the process evaluation, the performed and adhered components of the EASY-GO intervention are presented as frequencies and percentages.

\section{Ethics}

Ethical approval was obtained from the local ethics committee (CMO Arnhem-Nijmegen, \#2014-1400). All patients gave written and verbal informed consent to process their data.

\section{Results}

In total, 94 patients were included in the study's time frame (January 2015-January 2016): 47 before and 47 after implementation of the EASY-GO intervention (Figure 2). Twenty different surgeons were engaged with these 94 patients. In total, six consultants and five residents participated in the EASY-GO training. Only four trained surgeons consulted patients both before $(n=19)$ and after $(n=19)$ training and were consequently included in the analyses. All three nurse specialists completed the training to perform the geriatric screenings.

Characteristics of the included patients before and after training did not significantly differ (Table 1). PC patients were always seen by consultants, while CRC patients were also seen by residents. 


\section{Primary outcomes}

All PREMs showed a change in the direction of improved decision-making after training, but the $95 \%$ confidence intervals (95\% CIs) of the mean difference scores were wide (Table 2). Patient involvement as rated by surgeons also changed in the direction of improved decision-making. Before training, $13.3 \%$ of the patients mentioned that the decision was made by the doctor, $66.7 \%$ mentioned that the decision was made together with the doctor, and $20.0 \%$ mentioned that the decision was made by themselves or relatives. After training, these percentages were $20.0 \%, 73.3 \%$, and $6.7 \%$, respectively $(p=0.54)$. According to surgeons, $55.6 \%$ of the surgeons before training mentioned that the decision was made by them, $38.9 \%$ mentioned that the decision was made together with the patient or relatives, and $5.6 \%$ mentioned that the decision was made by the patient. After training, surgeons mentioned significantly more often that the decision was made together with the patient $(73.7 \%)$ and less often that the decision was made by them (15.8\%) $(p=0.04)$. A total of $10.5 \%$ mentioned that the decision was made by the patient and/or their relatives.
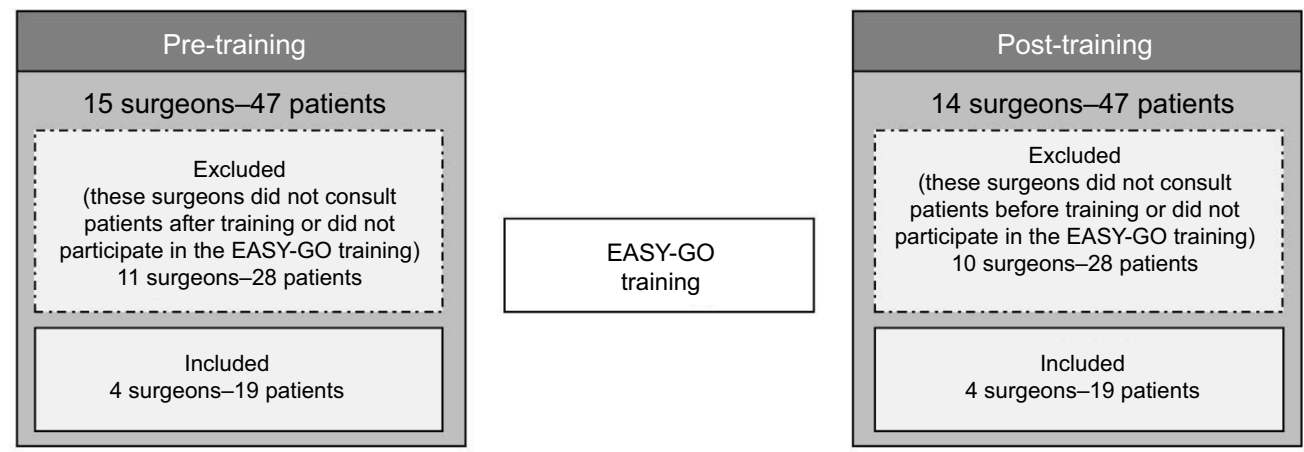

Figure 2 Flowchart that explains the number of surgeons and patients included in the study. Abbreviation: EASY-GO, EASYcare in Geriatric Onco-surgery.

Table I Patient characteristics before and after implementation of the EASY-GO intervention

\begin{tabular}{|c|c|c|c|c|c|}
\hline \multirow[t]{2}{*}{ Patient characteristics } & \multicolumn{2}{|l|}{ Before } & \multicolumn{2}{|l|}{ After } & \multirow[t]{2}{*}{ p-value* } \\
\hline & Total $n$ & Mean (SD) & Total $\mathbf{n}$ & Mean (SD) & \\
\hline Age (years) & 19 & 71.1 (5.9) & 19 & $72.1(4.4)$ & 0.56 \\
\hline Mean total number of medicines & 18 & $5.8(3.1)$ & 18 & $5.9(3.7)$ & 0.92 \\
\hline CIRS-G (total score) & 18 & I I.8 (4.8) & 19 & $13.5(4.0)$ & 0.24 \\
\hline \multicolumn{6}{|l|}{ KATZ-I5 } \\
\hline T0 & 17 & $0.6(1.5)$ & 15 & $1.2(2.5)$ & 0.36 \\
\hline TI & 15 & I.5 (2.6) & 14 & I.5 (3.2) & 0.98 \\
\hline \multicolumn{6}{|l|}{ EQ5D } \\
\hline T0 & 16 & $0.7(0.4)$ & 15 & $0.8(0.3)$ & 0.51 \\
\hline TI & 15 & $0.7(0.3)$ & 14 & $0.7(0.4)$ & 0.86 \\
\hline Length of hospital stay (days) & 11 & $13.3(10.5)$ & 14 & $12.2(6.7)$ & 0.76 \\
\hline \multirow[t]{2}{*}{ Mean total duration consultations (minutes) } & 16 & $35.8(14.9)$ & 16 & $36.2(16.2)$ & 0.94 \\
\hline & Total $\mathbf{n}$ & n (\%) & Total $\mathbf{n}$ & n (\%) & $p$-value \\
\hline Sex (female) & 19 & $9(47.4)$ & 19 & $6(31.6)$ & 0.32 \\
\hline Education level ${ }^{41}$ & 17 & & 19 & & 0.86 \\
\hline Low (Verhage I-4) & & II (54.7) & & II (57.9) & \\
\hline Middle (Verhage 5-6) & & $5(29.4)$ & & $6(31.6)$ & \\
\hline High (Verhage 7) & & I (5.9) & & $2(10.5)$ & \\
\hline Poly-pharmacy ( $\geq 5$ medicines) & 18 & $14(77.8)$ & 18 & $14(77.8)$ & 1.00 \\
\hline Diagnosis & 19 & & 19 & & 0.49 \\
\hline PC & & 14 (73.7) & & $13(68.4)$ & \\
\hline CRC & & $4(21.1)$ & & $6(31.6)$ & \\
\hline Others & & I (5.3) & & $0(0.0)$ & \\
\hline Diagnosis & 19 & & 19 & & 0.34 \\
\hline Malignant & & $13(68.4)$ & & 17 (89.5) & \\
\hline Pre-malignant & & $4(2 I .1)$ & & I (5.3) & \\
\hline Benign & & I (5.3) & & $0(0.0)$ & \\
\hline At risk & & I (5.3) & & I (5.3) & \\
\hline
\end{tabular}


Table I (Continued)

\begin{tabular}{|c|c|c|c|c|c|}
\hline & \multicolumn{2}{|l|}{ Before } & \multicolumn{2}{|l|}{ After } & \multirow[t]{2}{*}{ p-value } \\
\hline & Total $n$ & n (\%) & Total $n$ & n (\%) & \\
\hline Cancer stages (CRC) $)^{\ddagger}$ & 4 & & 6 & & 0.31 \\
\hline 0 & & $0(0.0 \%)$ & & I (I6.7\%) & \\
\hline I & & I (25.0\%) & & I (16.7\%) & \\
\hline ॥ & & $2(50.0 \%)$ & & $0(0.0 \%)$ & \\
\hline III & & $0(0.0 \%)$ & & I (16.7\%) & \\
\hline IV & & I (25.0\%) & & $3(50.0 \%)$ & \\
\hline \multicolumn{6}{|l|}{ Cancer stages $(\mathrm{PC})^{\ddagger}$} \\
\hline 0 & 14 & I (7.1\%) & 13 & $0(0.0 \%)$ & 0.45 \\
\hline $\mathrm{IA}$ & & $0(0.0 \%)$ & & $0(0.0 \%)$ & \\
\hline IB & & $0(0.0 \%)$ & & $3(23.1 \%)$ & \\
\hline IIA & & I (7.I\%\%) & & $2(15.4 \%)$ & \\
\hline IIB & & $2(14.3 \%)$ & & $3(23.1 \%)$ & \\
\hline III & & $2(14.3 \%)$ & & $2(15.4 \%)$ & \\
\hline IV & & $2(14.3 \%)$ & & I (7.7\%) & \\
\hline IPMN/NET & & $3(21.4 \%)$ & & I (7.7\%) & \\
\hline SCA/SCN & & I (7.I\%\%) & & I (7.7\%) & \\
\hline Unknown & & $2(14.3 \%)$ & & $0(0.0 \%)$ & \\
\hline Treatment (primary) & 19 & & 19 & & 0.59 \\
\hline Surgery (i.e. after neo-adjuvant therapy) & & $9(47.4)$ & & $12(63.2)$ & \\
\hline Radiotherapy and/or systemic therapy & & I (5.3) & & $2(10.5)$ & \\
\hline \multicolumn{6}{|l|}{ (neo-adjuvant) } \\
\hline Expectative & & $4(21.1)$ & & $2(10.5)$ & \\
\hline Palliative/palliative systemic therapy & & $2(10.5)$ & & $2(10.5)$ & \\
\hline TEM/EMR & & $0(0.0)$ & & I (5.3) & \\
\hline Refrained from treatment by the patient & & $\mathrm{I}(5.3)$ & & $0(0.0)$ & \\
\hline Unknown & & I (5.3) & & $0(0.0)$ & \\
\hline Complications (within 30 days after surgery) & 11 & $6(54.5)$ & 15 & II (73.3) & 0.32 \\
\hline Number of unplanned readmissions (within 30 days after surgery) & 11 & $3(27.3)$ & 15 & $2(13.3)$ & 0.37 \\
\hline ER visits (unplanned, due to the operation/tumor) & 9 & $5(55.6)$ & 15 & $4(26.7)$ & 0.16 \\
\hline ICU admission after surgery & II & $5(45.5)$ & 15 & $10(66.7)$ & 0.28 \\
\hline Adjuvant systemic therapy & 14 & & 12 & & 0.07 \\
\hline No & & II (78.6) & & $5(4 \mid .7)$ & \\
\hline Yes & & $3(21.4)$ & & $4(33.3)$ & \\
\hline Indicated, but refrained from by the patient & & $0(0.0)$ & & $3(25.0)$ & \\
\hline Mortality (within 30 days after SDM process) & 16 & $4(25.0)$ & 16 & $5(31.3)$ & 0.69 \\
\hline Type of surgeons & 18 & & 19 & & 0.16 \\
\hline Senior consultant & & $14(77.8)$ & & $12(63.2)$ & \\
\hline Junior consultant & & $2(11.1)$ & & $6(31.6)$ & \\
\hline Surgical resident & & $2(11.1)$ & & $0(0.0)$ & \\
\hline Combination & & $0(0.0)$ & & I (5.3) & \\
\hline Physician sex (female) & 18 & $7(38.9)$ & 19 & $8(42.1)$ & 0.84 \\
\hline Total number of conversations & 19 & & 19 & & 0.25 \\
\hline 0 & & $\mathrm{I}(5.3)$ & & $0(0.0)$ & \\
\hline I & & $6(31.6)$ & & $4(21.1)$ & \\
\hline$\geq 2$ & & $12(63.1)$ & & $15(78.9)$ & \\
\hline
\end{tabular}

Notes: * $p$-values were based on Student's t-test for continuous data, chi-square test for categorical data, and Fisher's exact test in case of small numbers per category; ${ }^{\text {based }}$ on the clinical TNM classification.

Abbreviations: CIRS-G, Cumulative Illness Rating Scale for Geriatric patients; CRC, colorectal cancer; EASY-GO, EASYcare in Geriatric Onco-surgery; EMR, endoscopic mucosal resection; EQ5D, EuroQol five dimensional scale (scale: $-0.33-1.00$, where I indicates the highest quality of life); ER, emergency room; ICU, intensive care unit; IMPN/NET, intraductal papillary mucinous neoplasm/neuroendocrine tumor; KATZ-I5, KATZ index of independence in activities and instrumental activities in daily living (scale 0-15, where 15 indicates the most disabilities); PC, pancreatic cancer; SCA/SCN, serous cystic neoplasm/serous cystadenoma; SDM, shared decision-making; TEM, transanal endoscopic microsurgery. T0, the baseline questionnaire was filled in after the final consultations when the treatment decision was made; TI, the follow-up questionnaire was filled in after three months;

\section{Secondary outcomes}

In accordance with the actual phase of the patients' treatment trajectories, quality of life and quality of functioning as secondary PROMs seemed to slightly worsen after three months both before and after training (Table 1). The difference in change in EQ5D scores before and after training was 
Table 2 Primary and secondary outcomes before and after implementation of the EASY-GO intervention

\begin{tabular}{|c|c|c|c|c|c|c|}
\hline & \multicolumn{2}{|c|}{ Before } & \multicolumn{2}{|c|}{ After } & \multirow[t]{2}{*}{ Difference score } & \multirow[t]{2}{*}{$95 \% \mathrm{Cl}$ of difference score } \\
\hline & $\bar{n}$ & Mean \pm SD & $\bar{n}$ & Mean \pm SD & & \\
\hline SDM-Q-9 & 17 & $74.5 \pm 27.8$ & 15 & $83.6 \pm 15.4$ & 9.05 & {$[-7.5 ; 25.6]$} \\
\hline VAS-I & 17 & $7.8 \pm 2.3$ & 15 & $8.2 \pm 1.9$ & 0.39 & {$[-1.1 ; 1.9]$} \\
\hline VAS-I $I_{d o c}$ & 17 & $7.0 \pm 1.6$ & 19 & $7.5 \pm 2.0$ & 0.53 & {$[-0.7 ; 1.8]$} \\
\hline VAS-S & 17 & $8.0 \pm I .4$ & 15 & $8.6 \pm 1.6$ & 0.58 & {$[-0.5 ; 1.7]$} \\
\hline DRS & 15 & $28.3 \pm 20.7$ & 14 & $19.6 \pm 21.4$ & -8.69 & {$[-24.7 ; 7.4]$} \\
\hline$\Delta$ EQ5D & 14 & $-0.1 \pm 0.3$ & 12 & $-0.1 \pm 0.2$ & -0.04 & {$[-0.3 ; 0.2]$} \\
\hline$\Delta$ KATZ-I5 & 15 & $1.1 \pm 2.5$ & 12 & $0.3 \pm 1.2$ & -0.73 & {$[-2.4 ; 0.9]$} \\
\hline
\end{tabular}

Abbreviations: DRS, Decisional Regret Scale (range 0-100, where 100 indicates the highest level of regret); EASY-GO, EASYcare in Geriatric Onco-surgery; SDM-Q-9, nine-item Shared Decision Making Questionnaire (range 0-100, where 100 indicates the highest extent of SDM); VAS-I, patient involvement on a visual analog scale (range 0-10, where 10 indicates the best score); VAS-I ${ }_{\text {doc }}$ : patient involvement on a visual analog scale according to the physician (range 0-10, where 10 indicates the best score); VAS-S, patient satisfaction on a visual analog scale (range 0-10, where 10 indicates the best score); $\Delta$ EQ5D, change in EuroQol five dimensional scale (scale: -0.33-1.00, where I indicates the highest quality of life) between TI and T0; $\Delta$ KATZ-I5, change in KATZ index of independence in activities and instrumental activities in daily living (I5 items, where 15 indicates the most disabilities) between $\mathrm{TI}$ and $\mathrm{TO}$.

Table 3 Primary and secondary outcomes per diagnosis before and after implementation of the EASY-GO intervention

\begin{tabular}{|c|c|c|c|c|c|c|}
\hline \multirow[t]{2}{*}{ PC } & \multicolumn{2}{|c|}{ Before } & \multicolumn{2}{|c|}{ After } & \multirow[t]{2}{*}{ Difference score } & \multirow[t]{2}{*}{$95 \% \mathrm{Cl}$ of difference score } \\
\hline & $\bar{n}$ & Mean \pm SD & $\bar{n}$ & Mean \pm SD & & \\
\hline SDM-Q-9 & 12 & $74.6 \pm 30.1$ & 10 & $88.0 \pm 12.3$ & 13.37 & {$[-7.9 ; 34.6]$} \\
\hline VAS-I & 12 & $8.5 \pm 1.3$ & 10 & $8.7 \pm 1.8$ & 0.27 & {$[-1.1 ; 1.6]$} \\
\hline VAS-I $I_{\text {doc }}$ & 13 & $6.6 \pm 1.7$ & 13 & $7.9 \pm 0.6$ & 1.23 & {$[0.2 ; 2.2]$} \\
\hline VAS-S & 12 & $8.0 \pm 1.6$ & 10 & $8.9 \pm 1.4$ & 0.88 & {$[-0.5 ; 2.2]$} \\
\hline DRS & 11 & $26.8 \pm 21.5$ & 10 & $16.5 \pm 16.0$ & -10.32 & {$[-27.8 ; 7.1]$} \\
\hline$\Delta$ EQ5D & 10 & $-0.0 \pm 0.4$ & 8 & $-0.1 \pm 0.3$ & -0.11 & {$[-0.5 ; 0.2]$} \\
\hline$\Delta$ KATZ-I5 & 11 & $1.5 \pm 2.9$ & 8 & $0.3 \pm 1.3$ & -1.20 & {$[-3.5 ; 1.1]$} \\
\hline \multirow[t]{2}{*}{ CRC } & \multicolumn{2}{|c|}{ Before } & \multicolumn{2}{|c|}{ After } & \multirow[t]{2}{*}{ Difference score } & \multirow[t]{2}{*}{$95 \% \mathrm{Cl}$ of difference score } \\
\hline & $\mathbf{n}$ & Mean \pm SD & $\mathbf{n}$ & Mean \pm SD & & \\
\hline SDM-Q-9 & 4 & $69.4 \pm 18.4$ & 5 & $74.7 \pm 18.4$ & 5.22 & {$[-29.5 ; 40.0]$} \\
\hline VAS-I & 4 & $5.4 \pm 3.4$ & 5 & $7.0 \pm 1.6$ & 1.63 & {$[-2.4 ; 5.6]$} \\
\hline VAS-I $I_{\text {doc }}$ & 4 & $8.2 \pm 1.1$ & 6 & $6.8 \pm 3.5$ & -1.39 & {$[-5.6 ; 2.8]$} \\
\hline VAS-S & 4 & $8.0 \pm 1.1$ & 5 & $8.0 \pm 1.9$ & 0.00 & {$[-2.5 ; 2.5]$} \\
\hline DRS & 3 & $23.3 \pm 11.5$ & 4 & $27.5 \pm 33.3$ & 4.17 & {$[-48.5 ; 56.8]$} \\
\hline$\Delta \mathrm{EQ} 5 \mathrm{D}$ & 3 & $-0.2 \pm 0.2$ & 4 & $-0.0 \pm 0.2$ & 0.16 & {$[-0.2 ; 0.5]$} \\
\hline$\Delta$ KATZ-I5 & 3 & $0.0 \pm 0.0$ & 4 & $0.5 \pm 1.0$ & 0.50 & {$[-1.0 ; 2.0]$} \\
\hline
\end{tabular}

Abbreviations: CRC, colorectal cancer; DRS, Decisional Regret Scale (range 0-100, where 100 indicates the highest level of regret); EASY-GO, EASYcare in Geriatric Onco-surgery; PC, pancreatic cancer; SDM-Q-9, nine-item Shared Decision Making Questionnaire (range 0-100, where 100 indicates the highest extent of SDM); VAS-I, patient involvement in the decision-making process on a visual analog scale (range 0-10, where 10 indicates the best score); VAS-I ${ }_{\text {doc }}$, patient involvement in the decisionmaking process on a visual analog scale according to the physician (range 0-10, where 10 indicates the best score), VAS-S, patient satisfaction concerning the decision-making process on a visual analog scale (range 0-10, where 10 indicates the best score); $\triangle$ EQ5D, change in EuroQol five dimensional scale (scale: $-0.33-1.00$, where I indicates the highest quality of life) between $\mathrm{TI}$ and T0; $\triangle \mathrm{KATZ}-15$, change in KATZ index of independence in activities and instrumental activities in daily living ( 15 items, where 15 indicates the most disabilities) between $\mathrm{TI}$ and $\mathrm{TO}$.

marginal (Table 2). The change in KATZ-15 scores seemed clinically relevant before training, where scores after training were mutually more comparable.

\section{Sub-analyses per diagnosis}

The quality of SDM and decisional regret among PC patients showed a clinically relevant change in the direction of improved decision-making after implementation (Table 3). The mean patient involvement score as rated by PC consultants significantly improved after training (VAS- $\mathrm{I}_{\mathrm{doc}}:+1.23$; 95\% CI: $0.2 ; 2.2$ ). Among CRC patients, only patient involvement showed a clinically relevant change in the direction of improved decision-making. Comparing the two diagnoses, PREMs were consistently better among PC patients after implementation (SDM-Q-9: +13.3 [95\% CI: $-3.8 ; 30.5]$; VAS-I: +1.73 [95\% CI: $-0.3 ; 3.8]$; VAS-S: $+0.9[95 \%$ CI: -1.0 ; 2.7]; DRS: -11.0 [95\% CI: $-38.9 ; 16.9]$ ).

\section{Quantitative process evaluation}

\section{Degree of implementation}

In total, $71.4 \%$ of the involved consultants, $42.9 \%$ of the involved residents, and $100 \%$ of the nurse specialists participated in the EASY-GO training. After training, 18 patients $(94.7 \%)$ received a geriatric screening as part of 
the EASY-GO working method. Only $16.7 \%$ of them were screened by nurse specialists. All others were screened by one of the researchers (NG). The geriatric screening results of 17 patients $(94.4 \%)$ were provided to the consultant or resident. The total duration of consultations did not significantly increase after training (Table 1).

\section{Discussion}

We piloted a training for surgeons and nurse specialists concerning SDM and a geriatric screening in the regular care processes for older patients with CRC or PC of our surgical department. The promising results in this study support the practical potential of the intervention's concept and its feasibility.

Though PREMs among trained surgeons showed a consistent change in the direction of improved decision-making, the wide confidence intervals of the mean difference scores suggest that significance could not be reached in our small sample size. Besides, the learning maximum was possibly not yet reached in our study since the ongoing training-onthe-job also belonged to the intervention's effect and each trained surgeon only consulted a few patients in the short study period. The effect on PREMs might have been bigger when the training-on-the-job period was expanded. The consistent change in PREMs in the direction of improved decisionmaking among PC patients, who were all consulted by trained consultants after implementation, suggests that the EASY-GO intervention was appropriate for this target group. Also the more dedicated regular care procedures for PC patients with less varying physicians may have contributed. Regarding older CRC patients among whom PREMs did not consistently change in the direction of improved decision-making, differences in the number and duration of consultations and differences in future health perspective may have contributed.

Previous studies concerning the effectiveness of SDM training programs for professionals show equivocal effects. ${ }^{28,29}$ The quality of evidence regarding SDM training generally is low and in surgical care virtually non-existing. Training programs vary extensively and only a few are sufficiently evaluated. ${ }^{29,30}$ Nevertheless, there is consensus about the need to improve patients' participation in decision-making and to implement SDM, ${ }^{30-32}$ whereby any kind of intervention that actively targets patients, physicians, or both is suggested to be better than none. ${ }^{29}$ Among physicians, SDM training programs are associated with increased confidence in their own SDM and interaction competencies, ${ }^{33}$ which correspond to our findings among trained PC surgeons. CRC surgeons, however, showed a clinically relevant change in patient involvement in the direction of worse decision-making after training. It is presumed that surgeons just realized after training what SDM is and thus whether they actually involve patients in decision-making. Because of the small total number of patients per surgeon, CRC surgeons could not develop their skills in practice.

Our pilot study has several strengths. Besides in older patients, we studied the effect of an SDM training in patients with PC or CRC, two cancer types with high perioperative morbidity and risk of decrease in quality of life and functioning. ${ }^{34}$ The practice-based design of our study favors it being representative for other hospitals. In addition, the general content of the EASY-GO training and working method makes the intervention, after only small changes, for example regarding information provision, applicable for other diagnoses and departments. We used relevant patient-reported experiences to evaluate the EASY-GO intervention. Specifically in clinical trials concerning patient-centered care, experience measures compared to outcomes measures are of additional value as quality indicators for personalized medicine. ${ }^{35-37}$ Moreover, patients and relatives were blinded for the training status of their surgeon. After training, patients received a geriatric screening including discussion of patients' life goals and treatment goals, which at least somewhat prepared patients for the consultation with their surgeon. ${ }^{28,29}$ Learning opportunities were optimal since our training was based on practice-based learning ${ }^{13,38}$ and comprised a short workshop including role plays with an actor and training-on-the-job. ${ }^{39}$

The study also has relevant limitations. We used a pragmatic pilot study with different patient groups before and after training, which complicated the interpretation of the results and possibly have obscured the effect of the intervention. We excluded all surgeons who only consulted patients before or after training reducing the sample size. In addition, only about half of the surgeons were trained decreasing the likelihood to demonstrate a positive effect of the intervention. However, in this pilot study, we aimed to present proof of concept of a training intervention such as the EASY-GO intervention including its practical barriers in order to optimize future study designs. Therefore, we did not intend to achieve appropriate target enrollment for statistical significance. With a voluntary training, we expect that the most motivated surgeons in SDM participated. This may have reduced the positive effect of the training due to relatively good initial SDM performance. ${ }^{33}$ Patients were seen by consultants or residents and PREMs were evaluated for different diagnoses, which both may have had an independent effect on the outcomes. Nevertheless, we found no significant differences in PREMs between consultants and residents at baseline and we additionally analyzed PREMs 
among PC patients who were all seen by trained consultants. Unclear is why CRC senior consultants as role models did not participate in the EASY-GO training. One reason may be an overestimation of their own SDM skills. ${ }^{40}$ Alternatively, the inclusion of several colon cancer patients with a less rigorous impact of the surgical procedure on quality of life may have resulted in a non-recognized equipoise of treatment options and unrecognized added value of the intervention. Due to time limits and logistic issues, one of the researchers accomplished most geriatric screenings instead of the nurse specialists. However, the nurse specialist was always present during the consultation with the surgeon corresponding to regular care and the researcher accomplished only the geriatric screening which may have limited a potential bias effect. Besides, the geriatric screening for nurse specialists was time-consuming: we planned 60 minutes per patient. However, screenings went more quickly with increasing practical experience, which made the screening more doable and acceptable for clinical practice.

Because of the practical potential of the intervention's concept and besides the limitations of our study design, we recommend to further investigate the effect of the EASY-GO intervention in a randomized controlled design on a larger scale using a mandatory training. Because of the promising results among PC patients, we recommend to start with this target group. Since the implementation of SDM and screening of the older patient's context are connected with each other, ${ }^{7}$ we advise to deliver both components simultaneously, for example, with help from nurse specialists. Ideally, it would also be investigated which component of the EASYGO intervention can contribute to what extent. Expanding and repeating the training-on-the-job period is desirable to maximize the learning effect. Since the geriatric screening lasted 30 minutes per patient for nurse specialists, time- and cost-related investments should be explored, as well as possibilities for defrayment and the most optimal interdisciplinary collaboration.

\section{Conclusion}

Results of this pilot study strengthen the idea that (the implementation of) a SDM training such as the EASY-GO intervention may have potential benefit among older surgical cancer patients.

\section{Acknowledgment}

This work was funded by the Dutch Cancer Society.

\section{Disclosure}

The authors report no conflicts of interest in this work.

\section{References}

1. Verweij NM, Schiphorst AH, Maas HA, et al. Colorectal cancer resections in the oldest old between 2011 and 2012 in the Netherlands. Ann Surg Oncol. 2016;23(6):1875-1882.

2. Brown SR, Mathew R, Keding A, Marshall HC, Brown JM, Jayne DG. The impact of postoperative complications on long-term quality of life after curative colorectal cancer surgery. Ann Surg. 2014;259(5):916-923.

3. Cooper Z, Koritsanszky LA, Cauley CE, et al. Recommendations for best communication practices to facilitate goal-concordant care for seriously Ill older patients with emergency surgical conditions. Ann Surg. 2016;263(1):1-6.

4. Okabayashi T, Shima Y, Iwata J, et al. Is a surgical approach justified for octogenarians with pancreatic carcinoma? Projecting surgical decision making for octogenarian patients. Am J Surg. 2016;212(5):896-902.

5. Fitzsimmons D, George S, Payne S, Johnson CD. Differences in perception of quality of life issues between health professionals and patients with pancreatic cancer. Psychooncology. 1999;8(2):135-143.

6. Verweij NM, Hamaker ME, Zimmerman DD, et al. The impact of an ostomy on older colorectal cancer patients: a cross-sectional survey. Int J Colorectal Dis. 2017;32(1):89-94.

7. Geessink NH, Schoon Y, van Herk HC, van Goor H, Olde Rikkert MG. Key elements of optimal treatment decision-making for surgeons and older patients with colorectal or pancreatic cancer: a qualitative study. Patient Educ Couns. 2017;100(3):473-479.

8. Levett DZ, Edwards M, Grocott M, Mythen M. Preparing the patient for surgery to improve outcomes. Best Pract Res Clin Anaesthesiol. 2016;30(2):145-157.

9. Ruiz M, Reske T, Cefalu C, Estrada J. Management of elderly and frail elderly cancer patients: the importance of comprehensive geriatrics assessment and the need for guidelines. Am J Med Sci. 2013;346(1):66-69.

10. Ugolini G, Ghignone F, Zattoni D, Veronese G, Montroni I. Personalized surgical management of colorectal cancer in elderly population. World J Gastroenterol. 2014;20(14):3762-3777.

11. Shipway DJ, Partridge JS, Foxton CR, et al. Do surgical trainees believe they are adequately trained to manage the ageing population? A UK survey of knowledge and beliefs in surgical trainees. J Surg Educ. 2015;72(4):641-647.

12. Schiphorst AH, Ten Bokkel Huinink D, Breumelhof R, Burgmans JP, Pronk A, Hamaker ME. Geriatric consultation can aid in complex treatment decisions for elderly cancer patients. Eur J Cancer Care (Engl). 2016;25(3):365-370.

13. van de Pol MH, Fluit CR, Lagro J, Slaats Y, Olde Rikkert MG, LagroJanssen AL. Shared decision making with frail older patients: proposed teaching framework and practice recommendations. Gerontol Geriatr Educ. 2017;38(4):482-495.

14. Elwyn. Shared decision making: a model for clinical practice. J Gen Intern Med. 2012;27(10):1361-1367.

15. Makoul. An integrative model of shared decision making in medical encounters. Patient Educ Couns. 2006;60(3):301-312.

16. Levinson W, Hudak P, Tricco AC. A systematic review of surgeon-patient communication: strengths and opportunities for improvement. Patient Educ Couns. 2013;93(1):3-17.

17. Snijders HS, Kunneman M, Bonsing BA, et al. Preoperative risk information and patient involvement in surgical treatment for rectal and sigmoid cancer. Colorectal Dis. 2014;16(2):O43-O49.

18. Cooper Z, Courtwright A, Karlage A, Gawande A, Block S. Pitfalls in communication that lead to nonbeneficial emergency surgery in elderly patients with serious illness: description of the problem and elements of a solution. Ann Surg. 2014;260(6):949-957.

19. Steffens NM, Tucholka JL, Nabozny MJ, Schmick AE, Brasel KJ, Schwarze ML. Engaging patients, health care professionals, and community members to improve preoperative decision making for older adults facing high-risk surgery. JAMA Surg. 2016;151(10):938-945.

20. Philip KE, Alizad V, Oates A, et al. Development of EASY-Care, for brief standardized assessment of the health and care needs of older people; with latest information about cross-national acceptability. $J \mathrm{Am} \mathrm{Med}$ Dir Assoc. 2014;15(1):42-46. 
21. van de Pol MH, Fluit CR, Lagro J, Slaats YH, Olde Rikkert MG, Lagro-Janssen AL. Expert and patient consensus on a dynamic model for shared decision-making in frail older patients. Patient Educ Couns. 2016;99(6):1069-1077.

22. Kriston L, Scholl I, Holzel L, Simon D, Loh A, Harter M. The 9-item Shared Decision Making Questionnaire (SDM-Q-9). Development and psychometric properties in a primary care sample. Patient Educ Couns. 2010;80(1):94-99.

23. Rodenburg-Vandenbussche S, Pieterse AH, Kroonenberg PM, et al. Dutch translation and psychometric testing of the 9-Item Shared Decision Making Questionnaire (SDM-Q-9) and Shared Decision Making Questionnaire-Physician Version (SDM-Q-Doc) in primary and secondary care. PLoS One. 2015;10(7):e0132158.

24. Brehaut JC, O'Connor AM, Wood TJ, et al. Validation of a decision regret scale. Med Decis Making. 2003;23(4):281-292.

25. Lutomski JE, Baars MA, Schalk BW, et al. The development of the Older Persons and Informal Caregivers Survey Minimum DataSet (TOPICS-MDS): a large-scale data sharing initiative. PLoS One. 2013; 8(12):e81673.

26. Degner LF, Sloan JA, Venkatesh P. The control preferences scale. Can J Nurs Res. 1997;29(3):21-43.

27. Singh JA, Sloan JA, Atherton PJ, et al. Preferred roles in treatment decision making among patients with cancer: a pooled analysis of studies using the control preferences scale. Am J Manag Care. 2010;16(9):688-696.

28. Dwamena F, Holmes-Rovner M, Gaulden CM, et al. Interventions for providers to promote a patient-centred approach in clinical consultations. Cochrane Database Syst Rev. 2012;12:CD003267.

29. Legare F, Stacey D, Turcotte S, et al. Interventions for improving the adoption of shared decision making by healthcare professionals. Cochrane Database Syst Rev. 2014(9):CD006732.

30. Diouf NT, Menear M, Robitaille H, Painchaud Guerard G, Legare F. Training health professionals in shared decision making: update of an international environmental scan. Patient Educ Couns. 2016;99(11):1753-1758.
31. Ochieng J, Buwembo W, Munabi I, et al. Informed consent in clinical practice: patients' experiences and perspectives following surgery. $B M C$ Res Notes. 2015;8:765.

32. Boss EF, Mehta N, Nagarajan N, et al. Shared decision making and choice for elective surgical care: a systematic review. Otolaryngol Head Neck Surg. 2016;154(3):405-420.

33. Bieber C, Nicolai J, Hartmann M, et al. Training physicians in shared decision-making - who can be reached and what is achieved? Patient Educ Couns. 2009;77(1):48-54.

34. Sperti C, Moletta L, Pozza G. Pancreatic resection in very elderly patients: a critical analysis of existing evidence. World J Gastrointest Oncol. 2017;9(1):30-36.

35. Calvert M, Blazeby J, Altman DG, Revicki DA, Moher D, Brundage MD. Reporting of patient-reported outcomes in randomized trials: the CONSORT PRO extension. JAMA. 2013;309(8):814-822.

36. Berman AT, Rosenthal SA, Moghanaki D, Woodhouse KD, Movsas B, Vapiwala N. Focusing on the "person" in personalized medicine: the future of patient-centered care in radiation oncology. J Am Coll Radiol. 2016;13(12 Pt B):1571-1578.

37. Huebner J, Rose C, Geissler J, et al. Integrating cancer patients' perspectives into treatment decisions and treatment evaluation using patient-reported outcomes - a concept paper. Eur J Cancer Care (Engl). 2014;23(2):173-179.

38. Kolb D. Experiential Learning: Experience as the Source of Learning and Development. Englewood Cliffs: Prentice Hall; 1984:20-38.

39. Heaven C, Clegg J, Maguire P. Transfer of communication skills training from workshop to workplace: the impact of clinical supervision. Patient Educ Couns. 2006;60(3):313-325.

40. Tyler Ellis C, Charlton ME, Stitzenberg KB. Patient-reported roles, preferences, and expectations regarding treatment of stage I rectal cancer in the cancer care outcomes research and surveillance consortium. Dis Colon Rectum. 2016;59(10):907-915.

41. Verhage F. Intelligence and Age in a Dutch Sample. Human Development. 1965;8:238-245.
Cancer Management and Research

\section{Publish your work in this journal}

Cancer Management and Research is an international, peer-reviewed open access journal focusing on cancer research and the optimal use of preventative and integrated treatment interventions to achieve improved outcomes, enhanced survival and quality of life for the cancer patient. The manuscript management system is completely online and includes

\section{Dovepress}

a very quick and fair peer-review system, which is all easy to use. Visit http://www.dovepress.com/testimonials.php to read real quotes from published authors. 